\title{
1 \\ Relationship between forest strata structure and regeneration in subtropical evergreen broad-leaved forest
}

\author{
Junsong Long ${ }^{1,2}$, Mengping Tang ${ }^{1,2, *}$
}

\section{$4 \quad$ Abstract}

5 Background: Regeneration is an extremely important and complex ecological process, which is disturbed by

many factors. The current stand structure has an important influence on regeneration. The aim of this study is to

provide theoretical reference for improving the regeneration capacity subtropical evergreen broad-leaved forest

8

*Correspondence: tmpzafu@163.com

${ }^{1}$ College of Environment and Resources, Zhejiang A\&F University, Hangzhou, 311300, China;

${ }^{2}$ Zhejiang Provincial Key Laboratory of Carbon Cycling in Forest Ecosystems and Carbon Sequestration, Hangzhou, 311300, China 
stratum.

Conclusions: The influencing order of each forest stratum structure on regeneration was: lower forest stratum > middle forest stratum > upper forest stratum. Different regeneration indicators had different responses to the main stand structure indices, while the young tree height and DBH, and the tree species diversity and density of regeneration trees were most affected by the main stand structure indices. In order to promote the regeneration of evergreen broad-leaved forest in the future, different management measures should be taken for different forest strata, and the threshold value of each index should be controlled.

Key words: subtropical evergreen broad-leaved forest; forest strata; stand structure; regeneration; redundancy analysis (RDA)

\section{Introduction}

Subtropical evergreen broad-leaved forest is one of the typical forest types in China, which plays an important role in protecting the environment and maintaining the global carbon balance and the sustainable development of human beings (Cao et al., 2010). However, due to the people's unreasonable development and utilization of forest resources in the early stage, the area of evergreen broad-leaved forest had been continuously reduced, resulting in the degradation of ecological functions and other problems (Song et al., 2005; Zhuo and Zheng, 2019). Natural regeneration is the main way of forest resources reproduction, which is particularly important for the restoration and protection of evergreen broad-leaved forest, and has great research and protection significance (Shi et al., 2014; Zhang et al., 2015). Natural regeneration is an extremely important and complex process of forest ecology, which goes through many growth stages (Chen et al., 2018). The success of each stage depends on many factors, so the research on the impact factors of natural regeneration had attracted people's attention.

The current stand structure is one of the main driving factors of regeneration (Boyden et al., 2005; Tinya et.al., 2019), which plays a key role in the succession and recovery of forest (Wan et al., 2019). The stand structure 
includes non-spatial structure and spatial structure. Non-spatial structure index was used to describe the average characteristics of the stand, which was not affected by the relative position of neighborhood trees (Gong et al., 2009; Tang, 2010). In recent years, there had been much researches on the relationship between non-spatial structure index and regeneration. The smallest beech seedlings regeneration was determined by stand structure indices to a greater extent (Žemaitis et al., 2019). Stand density had no significant effect on the number, base diameter and height of Pinus tabulaeformis seedlings (Chen and Cao, 2014). With the increase of canopy density, the density of different regeneration trees showed different trends (Zhang et al., 2010; Huang et al., 2018). Too large tree basal area and tree height of forest were not conducive to regeneration trees growth (Graber, 1976; Ou et al., 2017). Because the forest vertical structure largely determines the differences in the distribution of resources such as water, heat, light and nutrients in the forest (Jiang et al., 2015), it has an important effect on species growth, reproduction, death and resource utilization (Latham et al., 1998; Hao et al., 2007; Zhang et al., 2016; Zhuang et al., 2017; Nasiri et al., 2018). Therefore, the impact of forest vertical structure on regeneration had become one of the focuses of many scholars. In the canopy vertical structure, impact of the middle and lower layers on regeneration diversity was significantly higher than upper layer (Zhou et al., 2017). The higher the forest vertical structure diversity is, the more the favorable regeneration trees are (Donoso and Nyland, 2005). Too large or too small crown index would inhibit regeneration density, while regeneration density had a weaker correlation with small tree proportions, but showed a significant positive correlation with large tree proportions (Zhang et al., 2010). Ou et al. (2017) considered that the crown index, large and small tree proportions had no significant effect on the number of Excentrodendron hsienmu seedlings, but the effect on the seedling diameter and tree height was significant. With the gradual improvement of forest management level, stand spatial structure based on the relationship of neighborhood trees is one of the research priorities (Gong et al., 2009; Jiang et al., 2018). A few scholars had carried out the research on the relationship between spatial structure based on the relationship of 
neighborhood trees and regeneration, but most of their research used the artificially regeneration trees as object trees. For example, Zhang et al. (2004) pointed out that medium mingling and random distribution were suitable for artificial regeneration of Pinus koraiensis seedlings in the secondary forest. Luo et al. (2017) found that the average DBH and tree height of Pinus koraiensis seedlings in all experiment sites increased with the increase of opening degree in the same aspect. In summary, great achievements have been made on the impact of stand structure on natural regeneration, but the density, basal area, large and small tree proportions, canopy density, tree height and crown index of stand were mainly selected as stand structure indices in these studies, while few studies have reported the relationship between horizontal spatial structure index (aggregation index, competition index, mingling, etc) and natural regeneration. Therefore, it is great theoretical and practical significance to study the relationship between stand structure and natural regeneration by combining spatial structure with non-spatial structure.

In this study, the evergreen broad-leaved forest was divided into three forest strata in the plot. The non-spatial structure index of each forest stratum was determined by survey data, spatial structure index was calculated by using Voronoi diagram based on the relationship of neighborhood trees. Redundancy analysis was used to study the relationship between stand structure indices and regeneration indicators. The main purposes of this study were the following: (1) to understand the effect of dominant factors of whole forest structure and different forest stratum structure on regeneration; (2) to reveal the response of regeneration trees at different growth stages to dominant stand structure indices.

\section{Methods}

\subsection{Study area}

The study was conducted in the subtropical evergreen broad-leaved forest of Tianmu Mountain National Nature Reserve, Zhejiang province, China. It is located at latitude $30^{\circ} 18^{\prime} 30^{\prime \prime}$ to $30^{\circ} 24^{\prime} 55^{\prime \prime} \mathrm{N}$, longitude $119^{\circ} 24^{\prime} 11^{\prime \prime}$ 
90

91 elevation rising, soil type transits from subtropical red soil to wet temperate brown-yellow soil, with red soil below

600m, yellow soil between $600 \mathrm{~m}$ and $1200 \mathrm{~m}$, brown-yellow soil above $1200 \mathrm{~m}$. Forest types are diverse, including evergreen broad-leaved forest, deciduous broad-leaved mixed forest, deciduous dwarf forest, coniferous broad-leaved mixed forest, bamboo forest, etc.

We selected a representative section in the evergreen broad-leaved forest of Tianmu Mountain National Nature Reserve, and a permanent plot of $100 \mathrm{~m} \times 100 \mathrm{~m}$ was set up from July to August, 2005. This plot was divided into 25 survey units of $20 \mathrm{~m} \times 20 \mathrm{~m}$ by the adjacent grid survey method (Fig.1). Each grid was used as the investigation unit to measure all the trees in the plot, record each tree species, Coordinates $(\mathrm{x}, \mathrm{y}, \mathrm{z}), \mathrm{DBH}$, tree height and crown width. The main tree species were Cyclobalanopsis gracilis, Cyclobalanopsis glauca, Lithocarpus brevicaudatus, Litsea coreana, Cyclobalanopsis myrsinifolia. Meanwhile, all regeneration trees were investigated in each grid, record each tree species, $\mathrm{DBH}$, tree height and crown width. The main regeneration tree species were Camellia fraterna, Cyclobalanopsis gracilis, Litsea coreana, Cyclobalanopsis glauca, Lithocarpus

\section{brevicaudatus.}

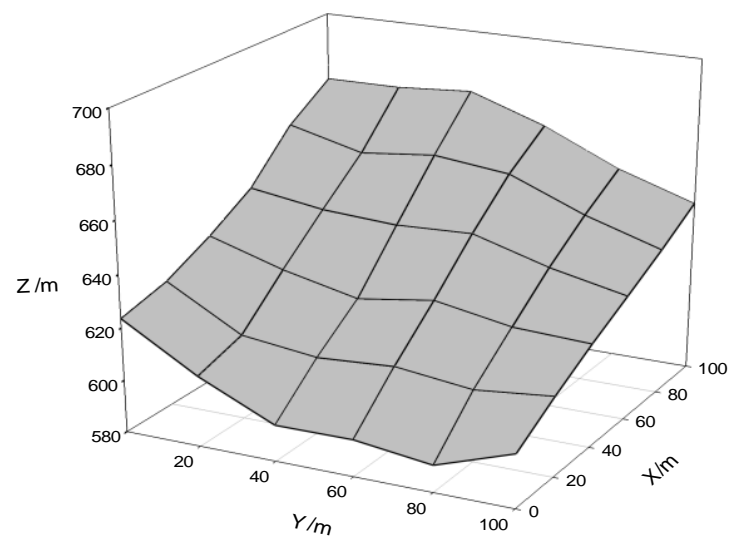

Fig.1 3D terrain map of the $10000 \mathrm{~m}^{2}$ plot 
height(h) as the stratification basis. The average of the highest 50 tree heights was taken as the stand dominant height in the plot, and then the difference value $(\Delta \mathrm{h})$ between the stand dominant height and the minimum tree height ( $h_{\min }$ ) was calculated. According to tree height $(\mathrm{H})$, the trees with $\mathrm{DBH} \geq 5 \mathrm{~cm}$ were divided into upper, middle and lower forest strata. Upper forest strata: $H>h_{\min }+2 / 3 \Delta h$, middle forest strata: $h_{\min }+1 / 3 \Delta h \leq H \leq$ $\mathrm{h}_{\min }+2 / 3 \Delta \mathrm{h}$, lower forest strata: $\mathrm{H}<\mathrm{h}_{\min }+1 / 3 \Delta \mathrm{h}$. The survey data calculated that the average stand dominant height was $17.2 \mathrm{~m}$, the minimum tree height was $1.5 \mathrm{~m}$ and the difference value was $15.7 \mathrm{~m}$. Therefore, upper forest strata: $\mathrm{H}>12 \mathrm{~m}$, middle forest strata: $6.7 \mathrm{~m} \leq \mathrm{H} \leq 12 \mathrm{~m}$, lower forest strata: $\mathrm{H}<6.7 \mathrm{~m}$.

\subsection{Stand structure indices}

\subsubsection{Stand non-spatial structure indices}

Trees with $\mathrm{DBH}>5 \mathrm{~cm}$ were defined as large trees, and DBH, tree height, crown width, density and diversity index were selected to describe the characteristics of stand non-spatial structure.

The tree species diversity index is used to describe the proportion of species to individuals in a biological community. The tree species richness index was calculated as (Liu et al., 2011):

$S=\frac{m-1}{\ln (M)}$

where, $S$ is tree species richness index, $m$ is the number of species in each grid, and $M$ is the total number of individuals of all species in the plot.

\subsubsection{Stand spatial structure indices}

Mingling, competition index and aggregation index were selected to describe the characteristics of stand spatial structure, and Voronoi diagram based on the relationship of neighborhood trees was used to calculate the stand spatial structure indices, i.e. the trees of which the Thiessen polygons are adjacent to the Thiessen polygon of 
133

$$
M c_{i}=\frac{1}{2}\left(D_{i}+\frac{c_{i}}{n_{i}}\right) \cdot M_{i}
$$

$$
C I=\frac{1}{Z} \sum_{i=1}^{Z} C I_{i}
$$
(Hegyi, 1974):

$$
C I_{i}=\sum_{j=1}^{n_{i}} \frac{d_{\mathrm{j}}}{d_{i} \cdot L_{i j}}
$$

where, $M_{i}$ is the mingling of the object tree $i ; M_{c i}$ is the complete mingling of the object tree $i ; N_{i}$ is the number of neighborhood trees; $V_{i j}$ is a discrete variable, $V_{i j}=1$ when the neighborhood tree $j$ and the object tree $i$ have different tree species, otherwise $V_{i j}=0 ; c_{i}$ is the number of different tree species in pairs of neighborhood trees in the spatial structure unit $i ; D_{i}$ is the Simpson diversity index of the tree species in the spatial structure unit $i$.

Competition index is used to describe the competitive relationship among trees within a forest. The Hegyi competition index (hereinafter referred to as competition index) based on Voronoi diagram was calculated as

143 where, $C I_{i}$ is the competition index of object tree $i, L_{i j}$ is the distance between object tree $i$ and neighborhood tree $j$, index. 
150

$$
R=\frac{\frac{1}{N} \sum_{i=1}^{N} r_{i}}{\frac{1}{2} \sqrt{\frac{F}{N}}}
$$

151

152

153

Where, $R$ is the aggregation index, $N$ is the number of trees in the plot, $F$ is the plot area, and $r_{i}$ is the distance from the object tree $i$ to its nearest neighborhood tree.

\subsection{Regeneration indicators}

The trees with $\mathrm{DBH}<5 \mathrm{~cm}$ were defined as regeneration trees. According to the tree height and DBH, the regeneration trees were divided into three grades: seedlings, saplings and young trees. Seedlings: $\mathrm{H} \leq 1.5 \mathrm{~m}, \mathrm{DBH}$ $<1 \mathrm{~cm}$; Saplings: $\mathrm{H} \leq 1.5 \mathrm{~m}, \mathrm{DBH} \geq 1 \mathrm{~cm}$; young trees: $\mathrm{H}>1.5 \mathrm{~m}, \mathrm{DBH}<5 \mathrm{~cm}$ (Tang et al., 2006). The DBH, tree height, crown width, species richness index and number of regeneration trees were selected as regeneration indicators. The species richness index was calculated by using Eq. (1).

\subsection{Data analyses}

The software IBM SPSS Statistics 20 was used to analyze the differences of different forest strata structure.

Redundancy analysis (RDA) is a direct gradient analysis method, which can intuitively analyze the complex relationship between multiple environmental factors and multiple species variables. The correlation between environmental factors and species variables is the product of the line length of species variables and the cosine of the angle between the environmental factors and species variables (Howard et al., 2012; Zhu et al., 2018). The stand structure indices were taken as environmental variables, and regeneration indicators as species variables, the relationship between them was analyzed using the software Canoco 5. Firstly, in order to select a suitable model for redundancy analysis, the data was subjected to the detrended correspondence analysis (DCA). When the 
maximum gradient of the four axes was less than or equal to 3, the linear model was used; when the maximum gradient was equal to or greater than 4, the unimodal model was used; when the maximum gradient was between 3 and 4, both models could be selected. Secondly, log transformation and centralization were performed on the original data. Variance inflation factor (VIF) was used to test the multicollinearity between variables, and the variance inflation factor was less than 20 , which indicated that there was no multicollinearity among the stand structure indices. The most significant stand structure indices affecting regeneration were screened out through interactive forward selection. Finally, the specific relationship between the most significant stand structure indices and regeneration indicators was further analyzed using "Multiple species response curve".

\section{Results}

\subsection{Differences in different forest strata structure}

Stand structure characteristics of different forest strata are shown in Table 1. There were significant differences among the different forest stratum structure index except the aggregation index $(\mathrm{p}<0.05)$. The mingling has significant differences between upper forest stratum and lower forest stratum, and no significant differences between middle forest stratum and other forest strata. The species richness index has significant differences between upper forest stratum and other forest strata, and no significant differences between middle forest stratum and lower forest stratum. With the rise of forest strata, the mingling increased, and the competition index and species richness index decreased. Therefore, it was reasonable to divide into three forest strata in this subtropical evergreen broad-leaved forest.

\begin{tabular}{ccccccccc}
\multicolumn{8}{c}{ Table 1 Stand structure characteristics of different forest strata } \\
\hline Stand & $\mathrm{M}$ & $\mathrm{CI}$ & $\mathrm{R}$ & $\mathrm{N}\left(\mathrm{no} \mathrm{*}^{-1} \mathrm{~h}^{-1}\right)$ & $\mathrm{DBH}(\mathrm{cm})$ & $\mathrm{H}(\mathrm{m})$ & $\mathrm{W}(\mathrm{m})$ & $\mathrm{S}$ \\
\hline Whole & $0.58 \pm 0.01 \mathrm{ab}$ & $8.93 \pm 0.26 \mathrm{~b}$ & $0.95 \pm 0.02 \mathrm{a}$ & $1629.00 \pm 102.38 \mathrm{a}$ & $12.70 \pm 0.34 \mathrm{c}$ & $7.17 \pm 0.17 \mathrm{c}$ & $3.58 \pm 0.15 \mathrm{c}$ & $3.72 \pm 0.20 \mathrm{a}$ \\
Upper & $0.61 \pm 0.02 \mathrm{a}$ & $4.13 \pm 0.50 \mathrm{~d}$ & $0.97 \pm 0.08 \mathrm{a}$ & $139.00 \pm 19.10 \mathrm{~d}$ & $30.98 \pm 1.35 \mathrm{a}$ & $14.80 \pm 0.41 \mathrm{a}$ & $5.58 \pm 0.22 \mathrm{a}$ & $0.86 \pm 0.14 \mathrm{c}$ \\
Middle & $0.59 \pm 0.01 \mathrm{ab}$ & $7.45 \pm 0.47 \mathrm{c}$ & $0.92 \pm 0.04 \mathrm{a}$ & $548.00 \pm 44.25 \mathrm{c}$ & $15.83 \pm 0.63 \mathrm{~b}$ & $8.50 \pm 0.09 \mathrm{~b}$ & $4.18 \pm 0.21 \mathrm{~b}$ & $2.41 \pm 0.15 \mathrm{~b}$ \\
Lower & $0.57 \pm 0.01 \mathrm{~b}$ & $10.49 \pm 0.37 \mathrm{a}$ & $0.97 \pm 0.03 \mathrm{a}$ & $942.00 \pm 75.96 \mathrm{~b}$ & $8.20 \pm 0.23 \mathrm{~d}$ & $5.02 \pm 0.04 \mathrm{~d}$ & $2.92 \pm 0.09 \mathrm{~d}$ & $2.44 \pm 0.15 \mathrm{~b}$ \\
\hline
\end{tabular}

Note: Different letters in the same column indicate a significant difference at the 0.05 level. M: mingling; CI: competition index; R: aggregation index; N: density; DBH: diameter at breast height; H: tree height; W: crown width; S: species richness index. 
197

\subsection{Effect of whole stand structure on regeneration}

The results of RDA showed that $49.22 \%$ of the regeneration variation was explained by the whole stand structure with $25.23 \%$ of that variation being explained from first axis and $19.68 \%$ from second axis, indicating

that the correlation between whole stand structure index and regeneration was mainly determined by the first axis and second axis. From the interactive forward selection results of whole stand structure indices, DBH, species richness index and crown width had the most significant effect on the regeneration, which the explained variations of regeneration were $18.4 \%, 9.4 \%, 7.2 \%$, accounting for about $71.11 \%$ of the explained variation of the 8 whole stand structure indices (Table 2).

Table 2 Summary of redundancy analysis results of whole stand structure and regeneration

\begin{tabular}{|c|c|c|c|c|c|c|c|}
\hline Name & Mean & Stand. dev. & Inflation factor & Explains \% & Contribution $\%$ & $\mathrm{~F}$ & $\mathrm{P}$ \\
\hline Wh_D & 12.69 & 1.68 & 3.78 & 18.4 & 36.1 & 5.2 & $0.006^{* * * *}$ \\
\hline Wh_S & 3.58 & 0.72 & 6.34 & 9.4 & 18.4 & 2.9 & $0.048 * *$ \\
\hline Wh_W & 3.72 & 0.96 & 3.97 & 7.2 & 14.1 & 2.3 & $0.07 *$ \\
\hline Wh_CI & 8.63 & 2.16 & 2.30 & 5.7 & 11.1 & 1.9 & 0.126 \\
\hline Wh_R & 1.00 & 0.22 & 3.21 & 3.9 & 7.6 & 1.3 & 0.256 \\
\hline Wh_H & 7.11 & 0.82 & 5.21 & 2.6 & 5.1 & 0.8 & 0.422 \\
\hline Wh_M & 0.57 & 0.07 & 2.10 & 2.4 & 4.8 & 0.8 & 0.484 \\
\hline \multirow[t]{4}{*}{ Wh_N } & 1629.00 & 501.58 & 4.14 & 1.4 & 2.8 & 0.5 & 0.762 \\
\hline & & & & Axis 1 & Axis 2 & Axis 3 & Axis 4 \\
\hline & & Eigenvalues & & 0.2523 & 0.1968 & 0.0276 & 0.0156 \\
\hline & Expla & variation (cu & ve) & 25.23 & 44.91 & 47.66 & 49.22 \\
\hline
\end{tabular}

Note: Wh_M, Wh_CI, Wh_R, Wh_S, Wh_DBH, Wh_H, Wh_W, Wh_N denotes the mingling, competition index, aggregation index, species richness index, diameter at breast height, tree height, crown width and density of the whole stand. $* * *: \mathrm{p}<0.01 ; * * \mathrm{p}<0.05 ; *: \mathrm{p}<0.1$.

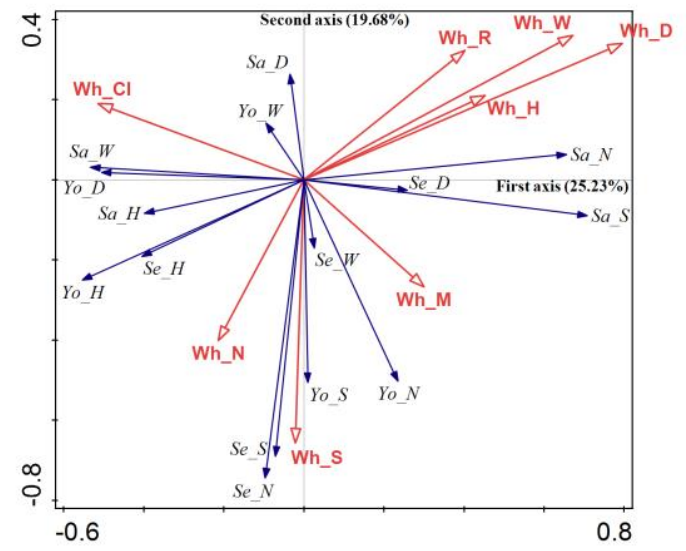

Fig. 2 RDA ordination diagram of whole stand structure indices and regeneration

Note: Hollow arrow represents stand structure indices, solid arrow represents regeneration indicators. Se_N, Se_D, Se_H, Se_W, Se_S denotes seedling density, diameter at breast height, tree height crown width and species richness index; Sa_N, Sa_D, Sa_H, Sa_W, Sa_S denotes sapling density, diameter at breast height, tree height,crown width and species richness index; Yo_N, Yo_D, Yo_H, Yo_W, Yo_S denotes young tree density, diameter at breast height, tree height, crown width and species richness index.

The ordination diagram of RDA showed that the DBH and crown width of whole stand had a strong positive effect on sapling density and species richness index, and a strong negative effect on young tree height and DBH. 
The species richness index of whole stand had a strong positive effect on seedling density and species richness index, and young tree density and species richness index (Fig. 2).

The specific effect of the dominant whole stand structure indices on regeneration is shown in Fig. 3. With the increase of the DBH in the whole stand, young tree height and DBH showed a decreasing trend, sapling species richness index showed an increasing trend, and sapling density showed a unimodal distribution. When the DBH of whole stand was between $13 \mathrm{~cm}$ and $15 \mathrm{~cm}$, sapling density maintained a high response value, young tree height and DBH tend to change stably, and the increasing trend of sapling species richness index slowed down (Fig. 3A).

With the increase of the species richness index in the whole stand, seedling density and species richness index showed an increasing trend, and young tree density and species richness index showed a unimodal distribution. The young tree density and species richness index kept a high response value when the species richness index of whole stand was between 4 and 5 (Fig. 3B). With the increase of the crown width in the whole stand, young tree DBH and height showed a single valley distribution, while sapling density and species richness index showed a unimodal distribution. Young tree DBH and height maintained a small response value when the crown width was between $4 \mathrm{~m}$ and $5.5 \mathrm{~m}$. The sapling density and species richness index maintained a high response value when the crown width of whole stand was between $4.5 \mathrm{~m}$ and $6 \mathrm{~m}$ (Fig. 3C).
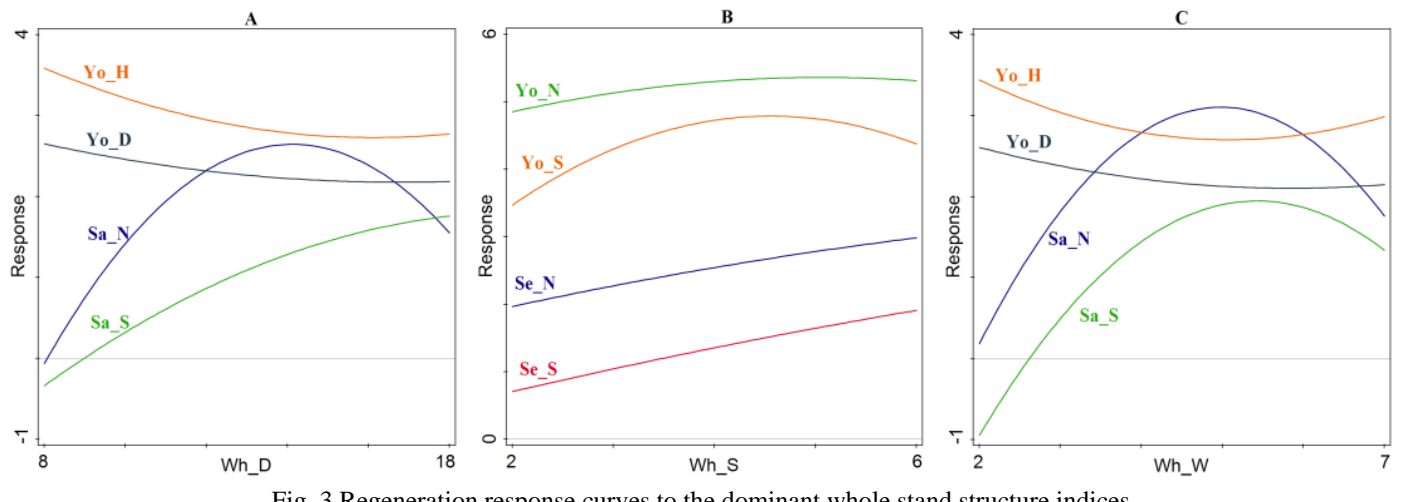

Fig. 3 Regeneration response curves to the dominant whole stand structure indices

\subsection{Effect of forest strata structure on regeneration}

\subsubsection{Effect of upper forest stratum structure on regeneration}




\begin{tabular}{|c|c|c|c|c|c|c|c|}
\hline Name & Mean & Stand. dev. & Inflation factor & Explains \% & Contribution $\%$ & $\mathrm{~F}$ & $\mathrm{P}$ \\
\hline Up_H & 14.8 & 2.0 & 2.2 & 13.9 & 35.9 & 3.7 & $0.02 * *$ \\
\hline Up_N & 139.0 & 93.6 & 9.7 & 6.5 & 16.7 & 1.8 & 0.134 \\
\hline Up_M & 0.6 & 0.1 & 1.8 & 6.3 & 16.3 & 1.8 & 0.116 \\
\hline Up_CI & 3.9 & 2.7 & 2.0 & 4.5 & 11.5 & 1.2 & 0.288 \\
\hline Up_W & 5.6 & 1.1 & 2.0 & 2.8 & 7.2 & 0.8 & 0.480 \\
\hline Up_R & 0.9 & 0.5 & 2.2 & 2.3 & 5.8 & 0.6 & 0.628 \\
\hline Up_S & 0.9 & 0.7 & 10.7 & 1.6 & 4.2 & 0.5 & 0.772 \\
\hline Up_D & 30.98 & 6.6 & 2.3 & 0.9 & 2.3 & 0.2 & 0.946 \\
\hline & & & Axis 1 & Axis 2 & Axis 3 & \multicolumn{2}{|c|}{ Axis 4} \\
\hline & Eigenv & & 0.1983 & 0.1087 & 0.0578 & \multicolumn{2}{|c|}{0.0128} \\
\hline Expl & d variatic & mulative) & 19.83 & 30.7 & 36.48 & \multicolumn{2}{|c|}{37.76} \\
\hline
\end{tabular}

Note: Up_M, Up_CI, Up_R, Up_S, Up_DBH, Up_H, Up_W, Up_N denotes the mingling, competition index, aggregation index, species richness index, diameter at breast height, tree height, crown width and density of the upper forest stratum.

The seedling height decreased with the increase of tree height in the upper forest stratum. When the tree 


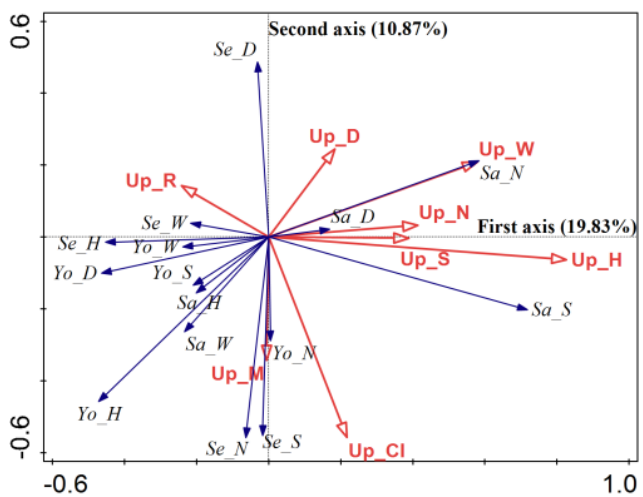

Fig. 4 RDA ordination diagram of upper forest stratum structure indices and regeneration

8 middle forest stratum structure indices.

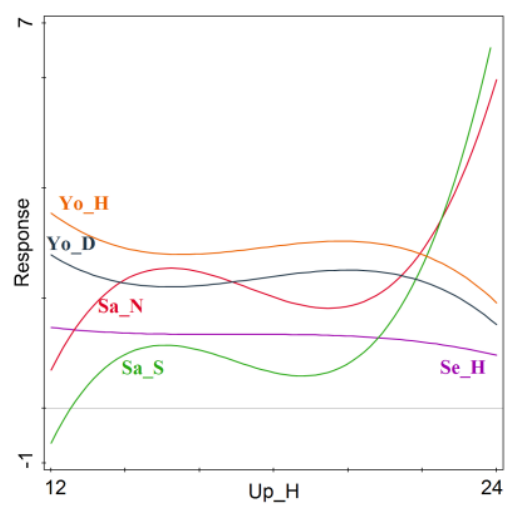

Fig. 5 Regeneration response curves to the dominant upper 249

\subsubsection{Effect of middle forest stratum structure on regeneration}

The redundancy analysis results of middle forest stratum structure and regeneration is shown in Table 4 .

$41.45 \%$ of the regeneration variation can be explained by the four axes, $38.26 \%$ of the regeneration variation can

be explained by the first two axes with $23.12 \%$ being explained by the first axis and $15.14 \%$ being explained by

the second axis. This shows that the first two axes can better explain the relationship between middle forest

stratum structure and regeneration. The significant structure factors were screened out by interactive forward

selection as follow: the tree species richness index and crown width of the middle forest stratum, which explained

$16.7 \%$ and $14.5 \%$ of the regeneration variation, accounting for about $75.27 \%$ of the total explained variation of the

\begin{tabular}{|c|c|c|c|c|c|c|c|}
\hline Name & Mean & Stand. dev. & Inflation factor & Explains \% & Contribution $\%$ & $\mathrm{~F}$ & $\mathrm{P}$ \\
\hline Mid_S & 2.4 & 0.7 & 3.8 & 16.7 & 39.0 & 4.6 & $0.006^{* * * *}$ \\
\hline Mid_W & 4.2 & 1.0 & 1.7 & 14.5 & 33.8 & 4.6 & $0.012 * *$ \\
\hline Mid_D & 15.8 & 3.1 & 1.8 & 4.2 & 9.7 & 1.4 & 0.262 \\
\hline Mid_M & 0.6 & 0.1 & 1.9 & 2.5 & 5.7 & 0.8 & 0.434 \\
\hline Mid_CI & 6.8 & 2.8 & 3.1 & 1.6 & 3.8 & 0.5 & 0.636 \\
\hline Mid_H & 8.5 & 0.4 & 1.9 & 1.6 & 3.7 & 0.5 & 0.694 \\
\hline Mid_N & 548.0 & 216.8 & 3.6 & 1.0 & 2.3 & 0.3 & 0.886 \\
\hline Mid_R & 0.98 & 0.3 & 2.9 & 0.8 & 2.0 & 0.2 & 0.934 \\
\hline & & & Axis 1 & Axis 2 & Axis 3 & \multicolumn{2}{|c|}{ Axis 4} \\
\hline \multicolumn{3}{|c|}{ Eigenvalues } & 0.2312 & 0.1514 & 0.0182 & \multicolumn{2}{|c|}{0.0137} \\
\hline \multicolumn{3}{|c|}{ Explained variation (cumulative) } & 23.12 & 38.26 & 40.08 & \multicolumn{2}{|c|}{41.45} \\
\hline
\end{tabular}

Note: Mid_M, Mid_CI, Mid_R, Mid_S, Mid_DBH, Mid_H, Mid_W, Mid_N denotes the mingling, competition index, aggregation index, species richness index, diameter at breast height, tree height, crown width and density of the Middle forest stratum. 


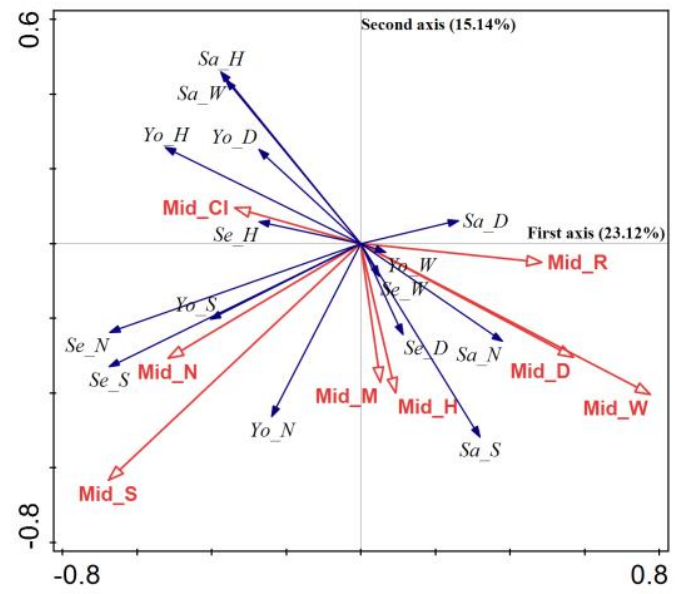

richness index first increased after reaching the minimum value, the increasing rate of seedling density slowed

forest stratum increased to between 3 and 3.5, the young tree species richness index reached the maximum value,

(Fig. 7A). With the increase of crown width in middle forest stratum, sapling crown width and young tree height the maximum value (Fig. 7B). 

for $78.06 \%$ of the total explained variation of the 8 stand structure indices.

290

\begin{tabular}{|c|c|c|c|c|c|c|c|}
\hline Name & Mean & Stand. dev. & Inflation factor & Explains \% & Contribution $\%$ & $\mathrm{~F}$ & $\mathrm{P}$ \\
\hline Low_W & 2.9 & 0.4 & 1.6 & 11.2 & 21.5 & 2.9 & $0.040 * *$ \\
\hline Low_CI & 10.3 & 3.3 & 1.6 & 10.8 & 20.9 & 3.3 & $0.034 * *$ \\
\hline Low_H & 5.0 & 0.2 & 1.3 & 9.5 & 18.3 & 2.6 & $0.044 * *$ \\
\hline Low_S & 2.4 & 0.8 & 3.6 & 7.2 & 13.8 & 2.3 & $0.070^{*}$ \\
\hline Low_M & 0.6 & 0.1 & 2.1 & 3.9 & 7.4 & 1.3 & 0.280 \\
\hline Low_N & 942.0 & 372.1 & 3.7 & 3.9 & 7.6 & 1.3 & 0.252 \\
\hline Low_D & 8.2 & 1.1 & 1.3 & 3.8 & 7.3 & 1.3 & 0.236 \\
\hline Low_R & 1.0 & 0.3 & 2.1 & 1.6 & 3.1 & 0.5 & 0.688 \\
\hline & & & Axis 1 & Axis 2 & Axis 3 & \multicolumn{2}{|c|}{ Axis 4} \\
\hline \multicolumn{3}{|c|}{ Eigenvalues } & 0.3009 & 0.1369 & 0.0423 & \multicolumn{2}{|c|}{0.0157} \\
\hline \multicolumn{3}{|c|}{ Explained variation (cumulative) } & 30.09 & 43.78 & 48.01 & \multicolumn{2}{|c|}{49.58} \\
\hline
\end{tabular}

The crown width of the lower forest stratum had a greater positive effect on sapling density and species

Fig. 7 Regeneration response curves to the dominant middle forest stratum structure indices

\subsubsection{Effect of lower forest stratum structure on regeneration}

The redundancy analysis results of lower forest stratum structure and regeneration is shown in Table 5 .

$49.58 \%$ of the regeneration variation can be explained by the four axes, $43.78 \%$ of the regeneration variation can

be explained by the first two axes with $30.09 \%$ being explained by the first axis and $13.69 \%$ being explained by

the second axis. Therefore, the first two axes provided the optimal explanation for the variation in both lower

forest stratum structure index and regeneration. From the forward selection results of lower forest stratum, the

most significant structure factors affecting regeneration were: crown width, competition index, tree height and species richness index, which the explained variation of regeneration were $11.2 \%, 10.8 \%, 9.5 \%, 7.2 \%$, accounting index, species richness index, diameter at breast height, tree height, crown width and density of the lower forest stratum.

richness index and a greater negative effect on seeding density and species richness index, and young tree density
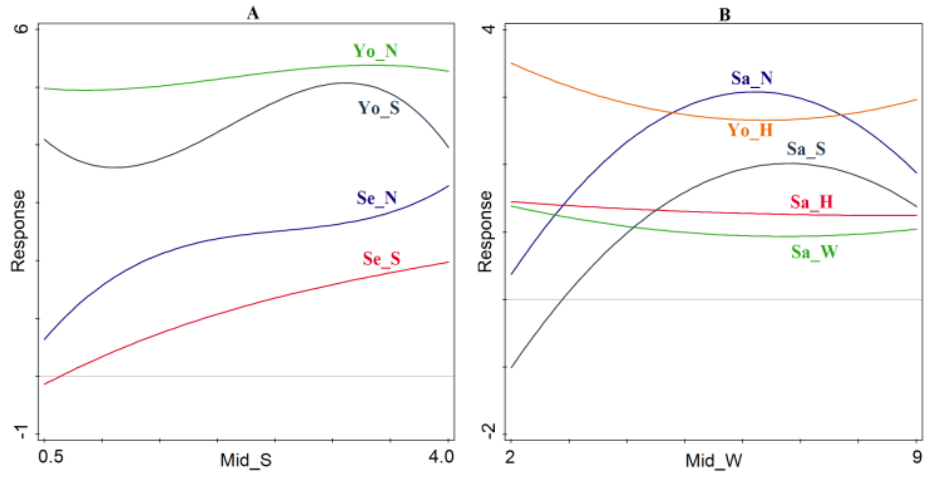
and height. The competition index of the lower forest stratum had a greater negative effect on regeneration tree density and species richness index. The tree height of the lower forest stratum had a greater negative effect on sapling density and species richness index, and a positive effect on young tree height and DBH. The tree species richness index in the lower forest stratum had a greater positive effect on seeding and young tree density and species richness index (Fig. 8).

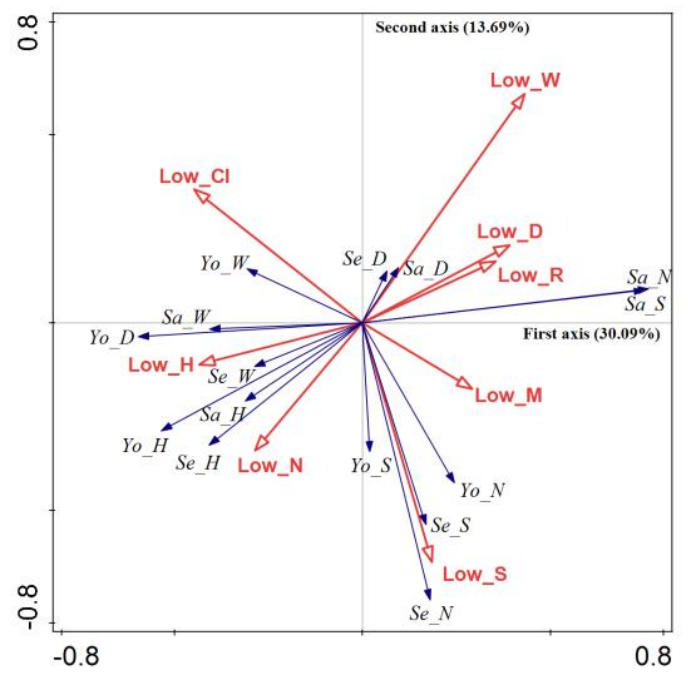

Fig. 8 RDA ordination diagram of lower forest stratum structure indices and regeneration

The specific effect of the main lower forest stratum structure indices on regeneration is shown in Fig. 9. When the crown width of the lower forest stratum was between $2.0 \mathrm{~m}$ and $3.2 \mathrm{~m}$, the seeding density and species richness index, and sapling density and species richness index had a single valley distribution, and sapling density and species richness index reached the minimum value. When the crown width of the lower forest stratum was between $3.2 \mathrm{~m}$ and $4.5 \mathrm{~m}$, the seeding density and species richness index, and sapling density and species richness index had a unimodal distribution, and sapling density and species richness index reached the maximum value (Fig. 9A). With the increase of competition index in the lower forest stratum, the seedling and sapling density and species richness index had a single valley distribution, the young tree density and species richness index showed downtrend. The seedling and sapling density and species richness index reached the minimum value when the 

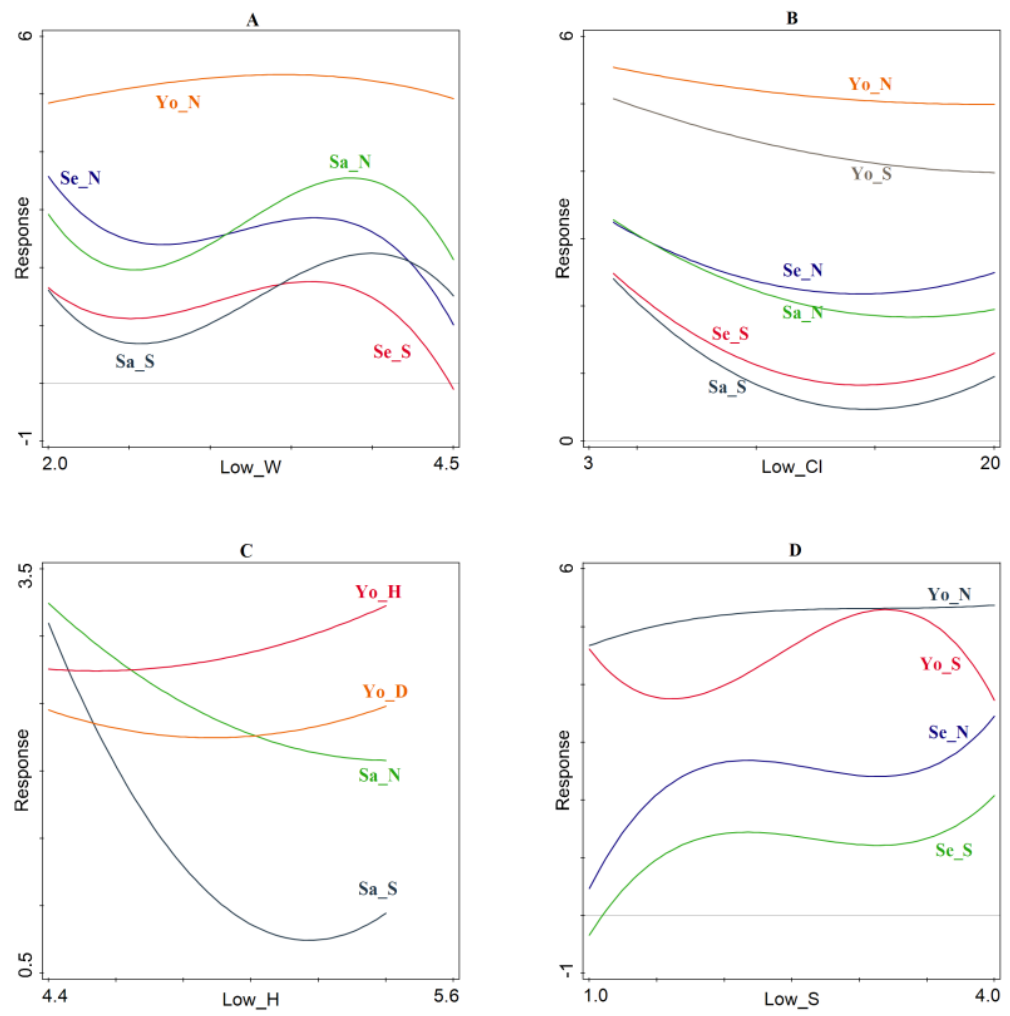

Fig. 9 Regeneration response curves to the dominant lower forest stratum structure indices 
327

\section{Discussion}

\subsection{Effect of whole stand structure on regeneration}

In the subtropical evergreen broad-leaved forest community, DBH, tree species richness index and crown width were the main whole stand structure indices affecting regeneration. The DBH and crown width of the whole stand could inhibit the individual size growth of regeneration trees, but to a certain extent could promote the regeneration of young tree density and species richness index, which is similar to the results of many scholars (Ou et al., 2017; Wu et al., 2019). It is generally believed that the larger DBH and crown width of the forest, the older stand age and the more mature seed trees in the forest, which can provide enough provenance for regeneration. Some researches showed crown width plays a role of shading and shelter for regeneration, and affects the growth of regeneration trees by changing habitat conditions such as light and humidity in the forest (Zhu et al., 2003; Yu et al., 2015; Huang et al., 2020). Our results clearly showed that the larger or smaller crown width of the whole stand could inhibit the regeneration of seedling density, sapling density and sapling species richness index, but could promote the growth of young tree height and DBH. Too small crown width causes abundant sunlight reaching the forest floor directly, some regeneration trees lose moisture easily and intolerant tree species may compete strongly with regeneration trees for the available resources, thereby reducing regeneration trees survival or growth (Lombaerde et al., 2019). If the crown width is too large, the photosynthesis of the regeneration trees is blocked and cannot grow well. Tree species richness was one of the main drivers affecting regeneration (Adam et al., 2013; Tinya et al., 2019). In this study, the species richness index of whole stand was positively correlated with the density and species richness of the regeneration trees. The reason may be that different tree species have different ways of regeneration (Shi et al., 2013), and the seed size and quality also have certain differences (Cheng et al., 2018), making them adaptable to different habitats. Therefore, in the regeneration management of subtropical evergreen broad-leaved forest in the future, the DBH, crown width and tree species richness index of the whole 
stand can be reasonably regulated according to the needs of the management objectives, so as to promote the regeneration.

\subsection{Effect of forest strata structure on regeneration}

The vertical stratification of tree crowns is a forest attribute that influences both tree growth and understory community structure (Latham et al., 1998). In the upper forest stratum, the tree height was the main stand structure factor affecting regeneration. In the middle forest stratum, the tree species richness index and crown width were the main stand structure indices affecting regeneration. In the lower forest stratum, the crown width, competition index, tree height and species richness index were the main stand structure indices affecting regeneration. The crown width and tree species richness index in the middle and lower forest strata had significant effects on the regeneration, which is similar to that found by Zhou et al. (2017). Compared to the effects of each forest strata and the whole stand on the regeneration, it is observed that the tree species richness index and crown width of the whole stand play a shelter role for regeneration trees and provide the seed source of dominant tree species which mainly comes from the middle and lower forest strata. Because the main dominant tree species in the middle forest stratum and the lower forest stratum were Cyclobalanopsis gracilis, Cyclobalanopsis glauca, Lithocarpus brevicaudatus, Camellia fraterna, etc., which had a large number and strong natural regeneration ability. While the number of trees in the upper forest stratum was relatively small, in addition to Cyclobalanopsis gracilis, Cyclobalanopsis glauca, Lithocarpus brevicaudatus, there were also deciduous species and coniferous species, such as Quercus fabri, Liquidambar formosana, Cunninghamia lanceolata, Torreya grandis, etc. The opening degree of object tree represents the light intensity in the forest where the object tree is located, and is defined as the sum of the proportion of the distance between object tree and its neighborhood trees to the neighborhood tree height (Luo et al., 1984; Luo et al., 2017). This indicates that the light intensity of a certain site in the forest is largely determined by the neighborhood trees height and the distance between the neighborhood trees and object 
371

trees. The tree height of the upper and lower forest strata had a significant impact on regeneration, because the tree height of the upper forest stratum is too high, which makes the light intensity and temperature increase in the forest, leading to the individual size growth of regeneration trees being inhibited. The increase of tree height of the lower forest stratum can provide the growth space for regeneration trees and reduce the competition for depletable resources, thus promote the individual size growth of regeneration trees. This research finding showed that the competition index of the lower forest stratum mainly affected the species richness index of regeneration trees. The smaller the competition index, the better the tree species diversity and density of regeneration. The smaller size and larger number of individuals in the lower forest stratum lead to the fierce competition for nutrients, living space and other resources by regeneration trees, which made the competition index of the lower forest stratum have significant effect on regeneration. The order of each forest stratum structure effect on regeneration was: lower forest stratum $>$ middle forest stratum $>$ upper forest stratum, which mainly affected the regeneration tree species richness index, as well as young tree height and DBH. Therefore, different management measures can be formulated for different forest strata to improve the regeneration ability or restoration of subtropical evergreen broad-leaved forest.

\section{Conclusions}

In this paper, redundancy analysis was used to study the relationship between different forest strata structure and regeneration, it can not only independently determine the contribution and explanation of each stand structure variable (Liu et al., 2011), but also reduce the number of stand structure variables that can effectively explain the regeneration variation. It can be seen from the ordination diagram of RDA that although the competition index of the whole stand and the crown width of the upper forest stratum had no significant effect on the regeneration, they had strongly correlated with sapling density and richness index. Hence the effect of non-significant stand structure indices on a certain regeneration indicator should not be neglected in the process of forest management. 
forest stratum > upper forest stratum. Different regeneration indicators had different responses to the main stand urgently needed in further study.

\section{Acknowledgments}

research.

\section{Author Contributions}

\section{Funding}


The authors declare that they have no competing interests.

\section{References}

Adam R, Odor P, Boloni J (2013) The effects of stand characteristics on the understory vegetation in Quercus petraea and Q. cerris dominated forests. Community Ecology 1: 101-109.

Boyden S, Binkley D, Shepperd W (2005) Spatial and temporal patterns in structure, regeneration, and mortality of an old-growth ponderosa pine forest in the Colorado Front Range. Forest Ecology and Management 219: 43-55.

Cao FY, Qi CJ, Yu XL, Xu QJ, Cao JW, Xu YF (2010) Conservational significances of evergreen broad-leaved forests in Central-China and the strategy of their restoration and rehabilitation. Journal of Central South University of Forestry and Technology 30: 95-104.

Chen Y.M, Cao Y (2014) Response of tree regeneration and understory plant species diversity to stand density in mature Pinus tabulaeformis plantations in the hilly area of the Loess Plateau, China. Ecological Engineering 73: 238-245.

Cheng RM, Shen YF, Feng XH, Xiao WF, Wang N, Yang S, Guo Y (2018) Research review on forests natural regeneration. Journal of Zhejiang Agriculture and Forestry University 35: 955-967.

Clark PJ (1954) Distance to nearest neighbor as a measure of spatial relationships in population. Ecology 35: 445-453.

Donoso PJ, Nyland RD (2005) Seedling density according to structure, dominance and understory cover in old-growth forest stands of the evergreen forest type in the coastal range of Chile. Revista Chilena de Historia Natural 1: 51-63.

Gong ZW, Kang XG, Gu L, Zhao JH, Zheng YF, Yang H (2009) Research methods on natural forest stand structure: a review. Journal of Zhejiang Forestry College 26: 434-443.

Graber WB (1976) Seedling input, death, and growth in uneven-aged northern hardwoods. Canadian Journal of Forest Research 3: 368-374.

Hao ZQ, Zhang J, Song B, Ye J, Li BH (2007) Vertical structure and spatial associations of dominant tree species in an old-growth temperate forest. Forest Ecology and Management 252: 1-11.

Hegyi (1974) A simulation model for managing perennial grass pastures.// Fries J.Growth Models for Tree and Stand Simulation. Stockholm: Royal College of Forestry 74-90.

Howard JH, Baldwin RF, Brown BL (2012) Exploratory analysis for complex-life-cycle amphibians: revealing complex forest-reproductive effort relationships using redundancy analysis. Forest Ecology and Management 270: 175-182.

Huang L, Zhu GY, Kang L, Hu S, Liu Z, Lu K (2019) Regeneration characteristics and related factors affecting saplings in Quercus spp. natural secondary forests in Hunan Province, China. Acta Ecologica Sinica 39: 4900-4909.

Huang P, Liu YH (2018) Effects of stand structure and terrain factors on seedling regeneration of Pinus tabuliformis forest in the Songshan National Nature Reserve, Beijing. Chinese Journal of Ecology 37: 1003-1009.

Huang RX, Jia XR, Liu T, Wu ZL, Xu MF, Su ZY (2020) Canopy structure and understory radiation dynamics of subtropical ecological public welfare forest. Journal of Northwest forestry University 35: 28-36.

Hui GY, Hu YB (2001) Measuring species spatial isolation in mixed forests. Forest Research 14: 23-27.

Jiang J, Lu YC, Pang LF, Zhang XQ, Li TT, Xing HT (2015) Structure of different stand layers and management optimization strategies in a Masson pine plantation in southern subtropical, China. Acta Ecologica Sinica 35: 44-50.

Jiang TS, Wang HZ, Dong LB, Chen Y, Liu ZG (2018) Effects of different intermediate cutting intensities on the spatial structure of Larix gmelinii forest. Journal of Northeast Forestry University 46: 9-14+19.

Kang B, Wang DX, Li G, Gao YX, Zhang Y, Du YL (2012) Characteristics of seedlings regeneration in Quercus aliena var. acuteserrata secondary forests in Qinling mountains. Acta Ecologica Sinica 32: 2738-2747.

Latham PA, Zuuring HR, Coble DW (1998) A method for quantifying vertical forest structure. Forest Ecology and Management 104: 157-170.

Liu XZ, Lu YC, Zhou YH, Lei XD, Zhang XQ, Meng JH (2011) The influence of soil conditions on regeneration establishment for degraded secondary forest restoration, Southern China. Forest Ecology and Management 261: 1771-1780.

Lombaerde ED, Verheyen k, Calster HV, Baeten L (2019) Tree regeneration responds more to shade casting by the overstorey and competition in the understorey than to abundance per se. Forest Ecology and Management 450: 117-129.

Luo Y, Shen HL, Zhang P, Lin ZX, Qi LY (2017) Effect of aspect on the diameter at breast height and height growth of Pinus koraiensis under the different opening degrees. Forest Engineering 33: 5-10.

Luo YH, Chen QC, Zhang PY (1984) The spatial pattern of coniferous forest in Xinglong mountain and its strategies in using sun light energy. Acta Ecologica Sinica 4: 10-20.

Madson P, Laisen JB (1997) Natural regeneration of beech (Fagus sylvatial L.) with respect to canopy density, soil moisture and soil carbon content. Forest Ecology and Management 97: 95-105.

Nasiri N, Marvie Mohadjer MR, Etemad V, Sefidi K, Mohammadi L, Gharehaghaji M (2018) Natural regeneration of oriental beech (Fagus orientalis Lipsky) trees in canopy gaps and under closed canopy in a forest in northern Iran. Journal of Forestry Research 29: 1075-1081.

Ou ZY, Pang SL, Tan ZQ, Zheng W, He QF, Shen WH (2017) Effects of forest structure on natural regeneration of Excentrodendron hsienmu population in Southwest Guangxi, China. Chinese Journal of Applied Ecology 28: 3181-3188.

Redmond MD, Kelsey KC (2018) Topography and overstory mortality interact to control tree regeneration in spruce-fir forests of the southern Rocky Mountains. Forest Ecology and Management 427: 106-113. 
Shi LL, Luo ZR, Xia JT, Zhao WJ, Wu YG, Ding BY (2014) Woody seedling dynamics and the correlation between habitat and regeneration / mortality in a subtropical evergreen broad-leaved forest in China. Acta Ecologica Sinica 34: 6510-6518.

Song YC, Chen XY, Wang XH (2005) Studies on evergreen broad-leaved of forests of China: a retrospect and prospect. Journal of East China Normal university $1: 1-8$.

Tang MP (2010) Advances in study of forest spatial structure. Scientia Silvae Sinicae 46: 117-122.

Tang MP, Chen YG, Shi YJ, Zhou GM, Zhao MS (2007) Intraspecific and interspecific competition analysis of community dominant plant populations based on Voronoi diagram. Acta Ecologica Sinica 27: 4707-4716.

Tang MP, Lou MH, Chen YG, Xu WB, Zhao MS (2012) Comparative analyses on different mingling indices. Scientia Silvae Sinicae 48: 46-53.

Tang MP, Zhou GM, Shi YJ, Chen YG, Zhao MS (2006) Study of dominant plant populations and their spatial patterns in evergreen broadleaved forest in Tianmu mountain, China. Journal of Plant Ecology 30: 743-752.

Tinya F, Márialigeti S, Bidló A, Ódor P (2019) Environmental drivers of the forest regeneration in temperate mixed forests. Forest Ecology and Management 433: 720-728.

Tyagi JV, Kumar R, Srivastava SL, Singh RD (2011) Effect of micro-environmental factors on natural regeneration of Sal (Shorea robusta). Journal of Forestry Research 22: 543-550.

Wan P, Zhang GQ, Wang HX, Zhao ZH, Hu YB, Zhang GG, Hui GY, Liu WZ (2019) Impacts of different forest management methods on the stand spatial structure of a natural Quercus aliena var. acuteserrata forest in Xiaolongshan, China. Ecological Informatics 50: 86-94.

Wu XQ, Yang SH, Huang L, Li XH, Yang C, Qian SH, Yang YC (2019) Effects of forest canopy condition on the establishment of Castanopsis fargesii seedlings in a subtropical evergreen broad-leaved forest. Chinese Journal of Plant Ecology 43: 55-64.

Yu B, Zhang QL, Wang LM (2015) Comprehensive characteristics of the vertical structure of middle young over cutting forest of Larix gmelinii. Scientia Silvae Sinicae 51: 132-139.

Žemaitis P, Wojciech G, Zbigniew B (2019) Importance of stand structure and neighborhood in European beech regeneration. Forest Ecology and Management 448: 57-66.

Zhang Q, Fan SH, Shen HL, Yang WH, Zhao KZ, Qi LY (2004) Influence of the spatial structure of tress, etc.on the young trees of Pinus koraiensis under natural secondary forest. Forest Research 17: 405-412.

Zhang SZ, Li M, Zhang SB, Zhang ZD, Huang XR (2015) Factors affecting natural regeneration of Larix principis-rupprechtii plantations in Saihanba of Hebei, China. Acta Ecologica Sinica 35: 5403-5411.

Zhang XP, Wang DX, Chang MJ, Kang HB, Zheng YY (2016) A review for effects of forest gap on forest regeneration and its microenvironment. Journal of Southwest Forestry University 36: 170-117.

Zhang ZD, Mao PL., Liu YH, Li QY, Liu SJ, Xue QZ (2010) Effects of forest structure on natural regeneration of Pinus thunbergii coastal shelter forest in Yantai region. Acta Ecologica Sinica 30: 2205-2211.

Zhou XG, Wen YG, Zhu HG, Wang L, Li XQ (2017) Canopy vertical structure and understory plant regeneration of an evergreen broadleaved forest in Damingshan, Guangxi, China. Chinese Journal of Applied Ecology 28: 367-374.

Zhou ZF, Zhang HR, Xu QG, Lie XD (2019) Analysis of inter-layer structure based on the relationship of neighboring trees. Journal of Beijing Forestry University 41: 66-75.

Zhu CC, Li QH, Chen WS, He Y, Xiao J (2018) Metazooplankton community structure and its relationship with environmental factors of Caohai, Guizhou Province, China. Ecological Science 37: 131-138.

Zhu JJ, Matsuzaki T, Li FQ, Gonda Y (2003) Effect of gap size created by thinning on seedling emergency, survival and establishment in a coastal pine forest. Forest Ecology and Management 182: 339-354.

Zhuang CY, Huang QL, Ma ZB, Zheng QR, Wang H (2017) Diameter distribution in each storey and law of typical natural broad-leaved forest in mid-subtropical zone. Scientia Silvae Sinicae 53: 18-27.

Zhuo Z, Zheng XX (2019) Forest structure and tree species diversity across a disturbance gradient in evergreen broadleaved secondary forests. Journal of Zhejiang Agriculture and Forestry University 36: 21-30. 